\title{
Identification of natural compounds targeting Annexin A2 with an anti-cancer effect
}

\author{
Yu-Shi Wang, He Li, Yang Li, Hongyan Zhu, Ying-Hua Jin ${ }^{\bowtie}$ \\ Key Laboratory for Molecular Enzymology and Engineering of the Ministry of Education, College of Life Science, Jilin \\ University, Changchun 130012, China \\ $\triangle$ Correspondence: yhjin@jlu.edu.cn (Y.-H. Jin) \\ Received November 7, 2017 Accepted January 24, 2018
}

\begin{abstract}
Annexin A2, a multifunctional tumor associated protein, promotes nuclear factor-kappa B (NF-KB) activation by interacting with NF-KB p50 subunit and facilitating its nuclear translocation. Here we demonstrated that two ginsenosides Rg5 (G-Rg5) and Rk1 (G-Rk1), with similar structure, directly bound to Annexin A2 by molecular docking and cellular thermal shift assay. Both Rg5 and Rk1 inhibited the interaction between Annexin A2 and NF-KB p50 subunit, their translocation to nuclear and NF-KB activation. Inhibition of NF-KB by these two ginsenosides decreased the expression of inhibitor of apoptosis proteins (IAPs), leading to caspase activation and apoptosis. Over expression of K302A Annexin A2, a mutant version of Annexin A2, which fails to interact with G-Rg5 and G-Rk1, effectively reduced the NF-KB inhibitory effect and apoptosis induced by G-Rg5 and G-Rk1. In addition, the knockdown of Annexin A2 largely enhanced NF-KB activation and apoptosis induced by the two molecules, indicating that the effects of G-Rg5 and G-Rk1 on NF-KB were mainly mediated by Annexin A2. Taken together, this study for the first time demonstrated that G-Rg5 and G-Rk1 inhibit tumor cell growth by targeting Annexin A2 and NF-kB pathway, and G-Rg5 and G-Rk1 might be promising natural compounds for targeted cancer therapy.
\end{abstract}

KEYWORDS Annexin A2, G-Rg5, G-Rk1, HCC, NF-kB

Electronic supplementary material The online version of this article (https://doi.org/10.1007/s13238-018-0513-z) contains supplementary material, which is available to authorized users.

\section{INTRODUCTION}

Annexin $\mathrm{A} 2$, a $\mathrm{Ca}^{2+}$-dependent lipid binding protein, widely distributed in nuclear, cytoplasm, endosomes and extracellular space and participates in various cellular process including signal transduction, endocytosis and exocytosis, proliferation, differentiation and apoptosis in mammalian cells (Klionsky et al., 2012; Moreau et al., 2011; Gerke et al., 2005; Moss and Morgan, 2004). A lot of evidence suggests that Annexin A2 may be a promising therapeutic target for cancer treatment (Chen et al., 2015; Staquicini et al., 2017; Kesavan et al., 2010; Wang et al., 2012). First, an accumulating observations have shown that Annexin A2 overexpressed in various types of cancer cells such as hepatocellular carcinoma (Zhang et al., 2012; Longerich et al., 2011; Sun et al., 2013), breast cancer (Deng et al., 2013; Chuthapisith et al., 2009; Shetty et al., 2012), lung cancer (Yao et al., 2009), gastric carcinoma (Zhang et al., 2012), pancreatic cancer (Takano et al., 2008), and colorectal cancer (Yang et al., 2013; Duncan et al., 2008). Second, the abnormal up-regulation of Annexin A2 enhances cancer development with higher aggression and poorer prognosis (Ohno et al., 2009; Ma et al., 2014; Yang et al., 2014). Third, forced inhibition of Annexin A2 effectively reduces tumor progression both in vitro and in vivo studies. Furthermore, signal transduction study has shown that Annexin A2 either promotes cancer cell metastasis by forming heterotetramer with S100A10 and binding with cell membrane (Réty et al., 1999), or largely enhances pro-survival capability and chemoresistance by activating transcription factors STAT-3 and nuclear factor-kappa B (NF-KB) (Tong et al., 2015; Jung et al., 2015).

$\mathrm{NF}-\mathrm{KB}$ is a transcription factor activating the expression of genes involved in inflammation, immune response, angiogenesis, cell proliferation and apoptosis (Perkins, 2012). Constitutive activation of NF-KB is a hallmark of several 
types of cancers, which not only promotes tumorigenesis and cancer development but also enhances drug resistance (Dolcet et al., 2005; Hanahan and Weinberg, 2000). Recent reports have shown that inhibition of NF-KB significantly inhibited cancer growth by directly inducing cancer cell apoptosis (Woo et al., 2016; Alexandersavino et al., 2016; Kwon et al., 2016; Yin et al., 2016; Hayden et al., 2008). Interestingly, the multifunctional tumor associated protein Annexin A2 promotes NF-KB activation via directly binding to NF-kB p50 subunit with its $\mathrm{N}$-terminal sequences, and inhibition of Annexin A2 provides a new regulatory tool on NF-KB activity (Jung et al., 2015).

Ginsenosides are the major bio-active component of ginseng (Attele et al., 1999) and ginsenoside Rg5 (G-Rg5) and Rk1 (G-Rk1) are the two main ginsenosides identified in heat processed ginseng (Toh et al., 2010). In the present study, we identified G-Rg5 and G-Rk1 that inhibited NF-kB activation, down-regulated the expression of IAPs and induced apoptosis by specifically binding to Annexin A2.

\section{RESULTS}

\section{G-Rg5 and G-Rk1 interacted with Annexin A2}

Molecular docking was first performed as a primary screening for natural compounds targeting Annexin A2. G-Rg5 bound to Annexin A2 with Glu296 and Lys302 responsible to this interaction (Fig. 1A). Cellular thermal shift assay (CTSA) with HepG2 cells demonstrated that G-Rg5 and G-Rk1 largely improved the thermal stability of Annexin A2, indicating the binding of G-Rg5 and G-Rk1 with Annexin. Exogenous wild-type Annexin A2 (Annexin A2-WT) showed a similar thermal stability shift under treatment of G-Rg5 and G-Rk1, while G-Rg5 and G-Rk1 didn't change the thermal stability of exogenous K302A mutant of Annexin A2 (Annexin A2-K302A), indicating Lys302 might be responsible for the interaction between Annexin $A 2$ and ginsenosides (Fig. 1B), as predicted by molecular docking. To rule out the effects from other cellular content and signaling towards the thermal stability of Annexin A2, we carried out the thermal shift assay with purified Annexin A2 and the two ginsenosides. Both G-Rg5 and G-Rk1 obviously enhanced the thermal stability of Annexin A2-WT but not Annexin A2$\mathrm{K} 302 \mathrm{~A}$ in a dose-dependent manner (Fig. 1C). These data indicated that both G-Rg5 and G-Rk1 directly bound to Annexin A2, and Lys302 is a critical residue for this interaction.

\section{G-Rg5 and G-Rk1 inhibited the interaction and nuclear co-localization of Annexin A2 and NF-KB p50 subunit}

In order to tell whether the G-Rg5 and G-Rk1 binding to Annexin A2 modulated the action of Annexin A2 in cells, we determined the interaction and nuclear co-localization of
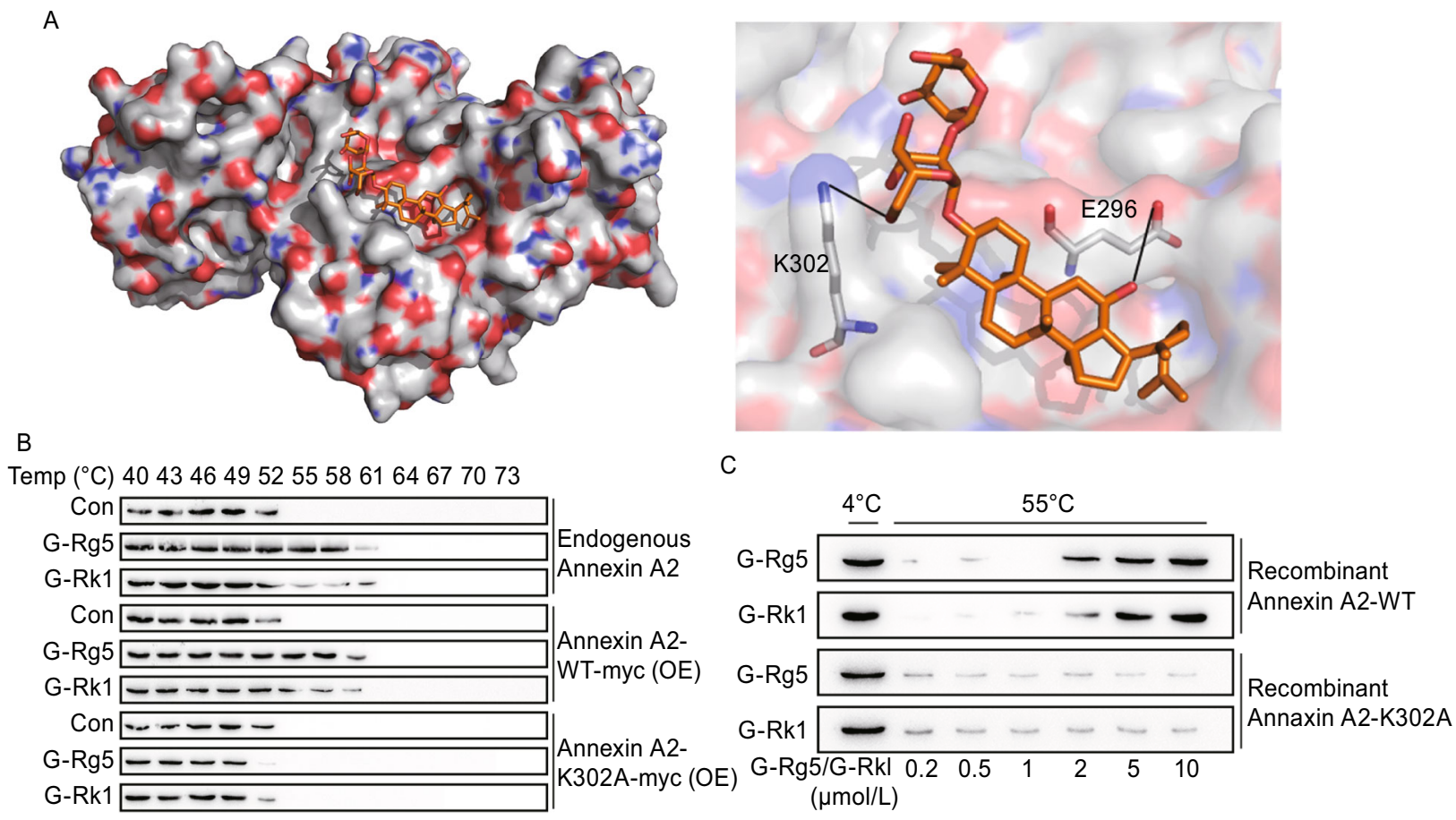

Figure 1. G-Rg5 and G-Rk1 bound to Annexin A2. (A) Results of molecular docking shows the interaction between Annexin A2 and G-Rg5. (B) Cellular thermal shift assay presented the thermal stability of Annexin A2 under treatment with G-Rg5 (12 $\mu \mathrm{mol} / \mathrm{L})$ and G-Rk1 (12 $\mu \mathrm{mol} / \mathrm{L})$. (C) Thermal shift in vitro showed the thermal stability of purified Annexin A2 $(0.2 \mu$ mol/L) under treatment with G-Rg5 and G-Rk1. 
Annexin A2 and NF-kB p50 subunit under G-Rg5 and G-Rk1 treatment. Immuno-precipitation was performed using HepG2 cells treated with $6 \mu \mathrm{mol} / \mathrm{L} \mathrm{G-Rg} 5$ or $6 \mu \mathrm{mol} / \mathrm{L}$ G-Rk1, with or without NF-KB activator PMA (100 ng/mL) or etoposide $(25 \mu \mathrm{g} / \mathrm{mL})$. The interaction between Annexin $A 2$ and NF-KB p50 was significantly attenuated under G-Rg5 and G-Rk1 treatment, both in resting cells and NF-KB activator treated cells (Fig. 2A). To rule out the possibility that the interaction was regulated by other eukaryotic cellular content, another immunoprecipitation was carried out with prokaryotic cell-expressed Annexin A2 and p50, and the interaction was also inhibited largely by G-Rg5 and G-Rk1 (Fig. 2B). Next, immunofluorescence was employed to examine the sub-cellular distribution of Annexin A2 and p50 under ginsenoside treatment. The nuclear co-localization of Annexin A2 and p50 was inhibited in both resting state and NF-KB activator-stimulating cells under G-Rg5 and G-Rk1 treatment (Fig. 2C). Taken together, G-Rg5 and G-Rk1 inhibited the interaction between Annexin A2 and p50, and their nuclear co-localization.

\section{G-Rg5 and G-Rk1 inhibited NF-KB activation and down- regulated downstream anti-apoptosis gene expression}

The activation of NF-KB was examined by dual luciferase reporter assay with HepG2 cells treated with G-Rg5 (6 $\mu \mathrm{mol} / \mathrm{L}), \mathrm{G}-\mathrm{Rk} 1(6 \mu \mathrm{mol} / \mathrm{L})$, etoposide $(25 \mu \mathrm{g} / \mathrm{mL})$ and PMA (100 ng/mL). G-Rg5 and G-Rk1 inhibited NF-kB

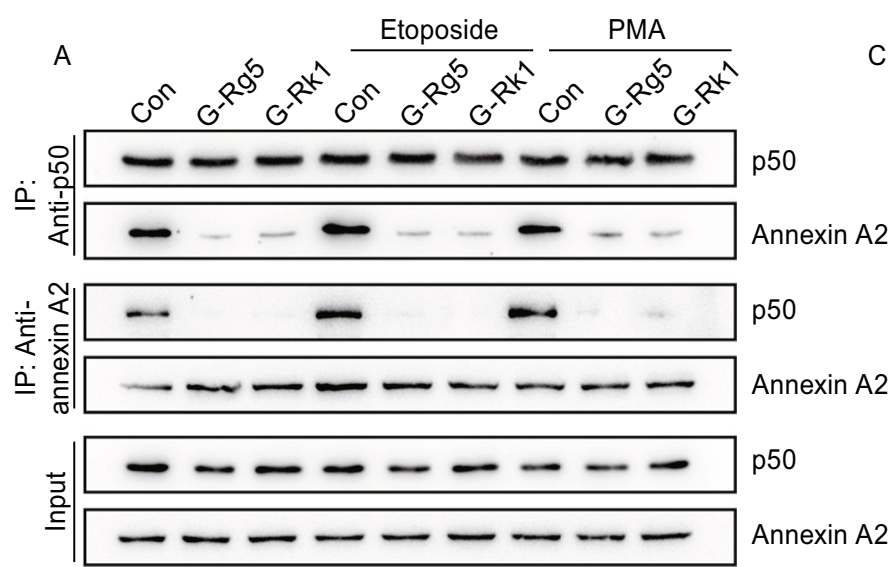

B

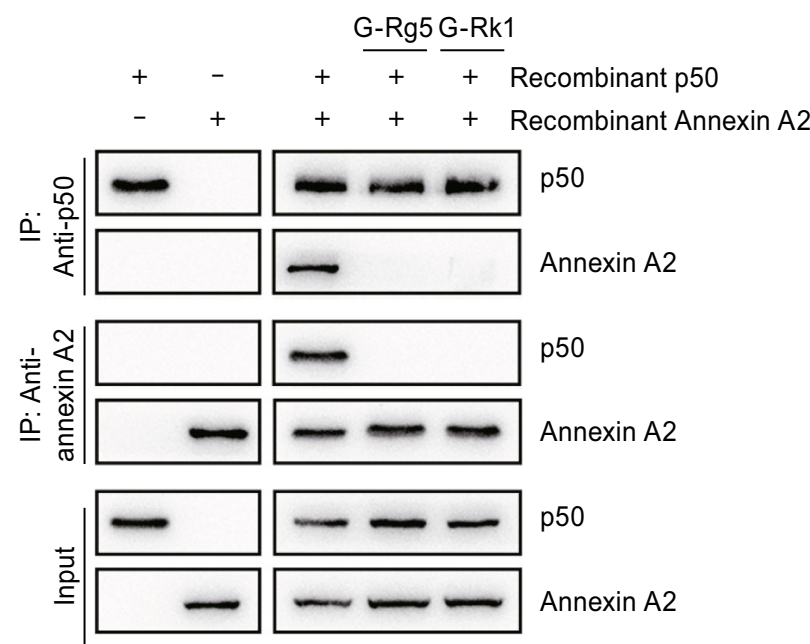

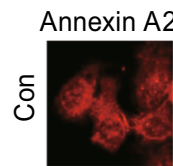
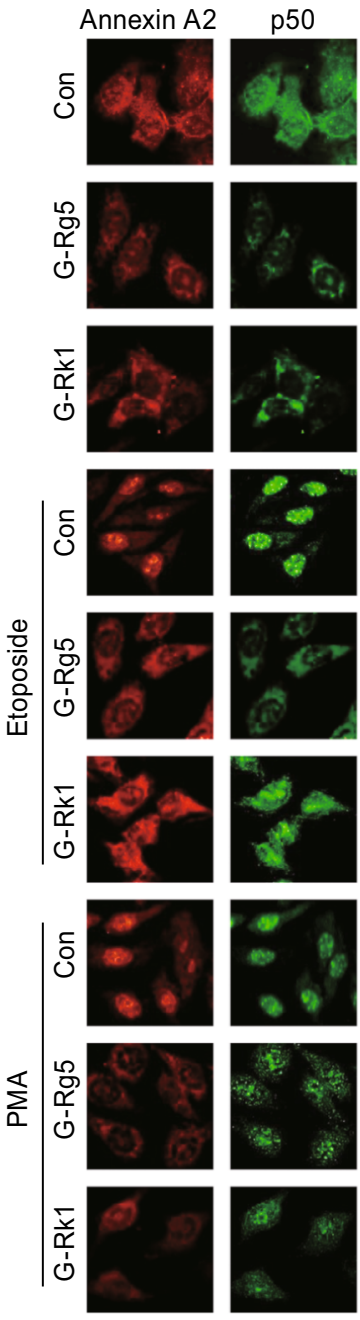


Figure 2. G-Rg5 and G-Rk1 inhibited interaction between Annexin A2 and NF-KB p50 subunit and their nuclear colocalization. (A) Immunoprecipitation was performed with whole-cell lysate of HepG2 cells under treatment with G-Rg5 (6 $\mu$ mol/L), G-Rk1 $(6 \mu \mathrm{mol} / \mathrm{L})$, etoposide $(25 \mu \mathrm{g} / \mathrm{mL})$ and PMA $(100 \mathrm{ng} / \mathrm{mL})$, and the interaction was analyzed by an immunoblot. (B) Immunoprecipitation was performed with prokaryotic cells-expressed Annexin A2 and NF-KB p50 subunit under treatment with G-Rg5 $(6 \mu \mathrm{mol} / \mathrm{L})$ and G-Rk1 $(6 \mu \mathrm{mol} / \mathrm{L})$, and the interaction was analyzed by an immunoblot. (C) The subcellular distribution of Annexin A2 and NF-kB p50 subunit was examined by immunofluorescence under treatment with G-Rg5 (6 $\mu \mathrm{mol} / \mathrm{L}), \mathrm{G}-\mathrm{Rk} 1$ ( $6 \mu \mathrm{mol} / \mathrm{L})$, etoposide $(25 \mu \mathrm{g} / \mathrm{mL})$ and PMA $(100 \mathrm{ng} / \mathrm{mL})$, and DAPI showed the nuclear region. 



Figure 3. G-Rg5 and G-Rk1 inhibited NF-KB activation and down-regulated downstream anti-apoptosis genes. (A) NF-KB activity was examined by luciferase reporter assay under treatment with G-Rg5 $(6 \mu \mathrm{mol} / \mathrm{L}), \mathrm{G}-\mathrm{Rk} 1(6 \mu \mathrm{mol} / \mathrm{L})$, etoposide $(25 \mu \mathrm{g} / \mathrm{mL})$ and PMA (100 ng/mL). (B-F) Relative gene expression levels of IL-6 (B), X-IAP (C), C-IAP1 (D), C-IAP2 (E) and survivin (F) were examined by qRT-PCR under treatment with G-Rg5 $(6 \mu \mathrm{mol} / \mathrm{L})$, G-Rk1 $(6 \mu \mathrm{mol} / \mathrm{L})$, etoposide $(25 \mu \mathrm{g} / \mathrm{mL})$ and PMA $(100 \mathrm{ng} / \mathrm{mL})$. (G) Protein levels of X-IAP, c-IAP1, C-IAP2 and survivin were examined by immunoblot under treatment with G-Rg5 (6 $\mu \mathrm{mol} / \mathrm{L})$, G-Rk1 $(6 \mu \mathrm{mol} / \mathrm{L})$, etoposide $(25 \mu \mathrm{g} / \mathrm{mL})$ and PMA $(100 \mathrm{ng} / \mathrm{mL})$, and $\beta$-actin was shown as a loading control. All data are shown as the mean $\pm \mathrm{SD}$ and the experimental points show the average of at least triplicates. All experiments were repeated at least 3 times.

activation in resting state and under treatment with etoposide and PMA, activator enhancing NF-KB activity (Fig. 3A). The similar inhibitory effect was observed to downstream genes of NF-KB like IL-6 (Fig. 3B), a classic NF-KB activating gene, and IAPs genes including X-IAP, C-IAP1, C-IAP2 and survivin (Fig. 3C-F). The protein levels of X-IAP, C-IAP1, C-IAP2 and survivin were also down-regulated by G-Rg5 and G-Rk1, in both resting and NF-KB activator-stimulated cells (Fig. 3G).

\section{Annexin A2 knock-down enhanced anti-cancer activity of G-Rg5 and G-Rk1 in HepG2 cells}

To examine whether Rg5 inhibits NF-kB activation primarily by Annexin A2, knock-down of Annexin A2 was employed with shRNA vectors. Both Annexin A2 knock-down and
G-Rg5 inhibited NF-KB activation, and the inhibitory effect of G-Rg5 was largely enhanced by Annexin A2 knock-down at the moderate concentration $(6 \mu \mathrm{g} / \mathrm{mL})$, and at the high dose of G-Rg5 $(6 \mu \mathrm{g} / \mathrm{mL})$, Annexin A2 knock-down showed little effect (Fig. 4A), which indicates G-Rg5 regulating NF-KB mainly through Annexin A2. Caspase 3 and 9 was activated under G-Rg5 treatment, which was also enhanced by Annexin A2 knock-down (Fig. 4B and 4C). MTT assay showed the anti-survival activity of G-Rg5, which was also enhanced by Annexin A2 knock-down (Fig. 4D). G-Rk1 behaved in a similar manner to G-Rg5 on NF-kB inhibition (Fig. 4E), caspase activation (Fig. $4 \mathrm{~F}$ and $4 \mathrm{G}$ ) and antiproliferation activity (Fig. $4 \mathrm{H}$ ). A plate clone formation assay showed that G-Rg5 and G-Rk1 inhibited clone formation of HepG2 cells and Annexin A2 knock-down intensified this 
inhibitory effect (Fig. 4I), as expected. Taken together, G-Rg5 and G-Rk1 inhibited proliferation of HepG2 cells, which might be mainly mediated by Annexin A2.

\section{K302A Annexin A2 protected cells from cytotoxic effect induced by G-Rg5 and G-Rk1}

To further provide evidence for the major role of Annexin A2 in G-Rg5 and G-Rk1-induced NF-kB inhibition, studies were carried out with exogenous Annexin A2-K302A, a mutant version, which fails to interact with G-Rg5 and G-Rk1. First, immunoprecipitation was performed with Annexin A2-WT or Annexin A2-K302A over-expressed HepG2 cells with G-Rg5 and G-Rk1 treatment. Both chemicals attenuated the interaction between p50 and Annexin A2-WT, which was either endogenous or myc-tagged exogenous. However these two chemicals failed to reduce the interaction between $p 50$ and Annexin A2-K302A, appeared to promote this interaction (Fig. 5A). An in-vitro immunoprecipitation using prokaryotic cell expressed p50 and Annexin A2-K302A showed that p50 and Annexin A2-K302A did interact with each other, and either chemicals failed to affect this interaction (Fig. 5B). Immunocytochemistry clearly showed that wild type of Annexin A2 (either endogenous or exogenous) failed to colocalize to nuclear with $\mathrm{p} 50$ under treatment of $\mathrm{G}-\mathrm{Rg} 5$ and G-Rk1 (Fig. 5C), while the two chemicals promoted the nuclear co-localization of Annexin A2-K302A.

Next, NF-kB activation was examined in Annexin A2-WT or Annexin A2-K302A overexpressed HepG2 cells. Overexpression of Annexin A2-WT enhanced NF-KB activation, and G-Rg5 inhibited NF-KB activity in a dose-dependent manner both in mock transfected and in Annexin A2-WT expressed HepG2 cells. Interestingly, G-Rg5 didn't inhibit, even enhance NF-KB activity in Annexin A2-K302A overexpressed HepG2 cells (Fig. 6A). Activation of caspase 9 and 3 was attenuated when Annexin A2-WT was overexpressed, and only slight activation was detected with an over-expression of Annexin-K302A (Fig. 6B and 6C). Similarly, Annexin A2-K302A abolished the inhibition of NF-KB induced by G-Rk1 (Fig. 6D). G-Rk1 induced weaker caspase activation in Annexin A2-WT over-expressing cells and a little caspase activation was observed in Annexin A2-K302A over-expressing cells compared with mock transfected cells (Fig. 6E and 6F). Anti-proliferation activity was examined by MTT assay and plate clone formation assay with Annexin A2-WT or Annexin A2-K302A over-expressing HepG2 cells. Both Annexin A2-WT and Annexin A2-K302A over-expression rendered cells to resist the cytotoxic effect of G-Rg5 and G-Rk1, and the activity of Annexin A2-K302A showed higher than that of Annexin A2-WT (Fig. 6G and 6H).

\section{DISCUSSION}

Annexin A2, a multi-functional cancer associated protein, promotes cancer progress in a list of mechanisms. In this report we developed an assay for screening small-molecule modulator of Annexin A2 and identified two Annexin A2 regulating compounds G-Rg5 and G-Rk1 (Fig. 1A). A recent report has shown that both G-Rg5 and G-Rk1 inhibited NF-KB activation and related immuno-response in HepG2 cells (Lee, 2015). G-Rg5 and G-Rk1 directly bound to Annexin $A 2$ and disturbed the interaction between Annexin A2 and NF-KB p50 (Figs. 1 and 2), which leaded to the cytosol-retention of these two proteins and resulted in the inactivation of NF-KB transcriptional activity. IAPs, the NF-KB downstream genes were down-regulated, and caspase- 3 and -9 were activated by the treatment of either compound (Fig. 3).

As described, Annexin A2 binds to NF-KB p50 subunit, and promotes NF-KB activation, which might promote the pro-survival effect and chemoresistance in tumor tissues (Tong et al., 2015; Staquicini et al., 2017; Das et al., 2010). The N-terminal of Annexin A2 is necessary for the interaction between Annexin A2 and NF-kB p50 (Jung et al., 2015). A recent report demonstrates that Lys302 of Annexin A2 contributes to the conformational stability of its $\mathrm{N}$-terminal, and promoting the interactions with other proteins driven by this sequence (Ecsédi et al., 2017). The interaction between Annexin A2 and p50 may possibly follow this pattern, and modifications towards Lys302 will probably regulate the activation of NF-KB.

G-Rg5 and G-Rk1 triggered multiple cellular events, which possibly participated in NF-KB activation, however, this activation was dominantly inactivated by G-Rg5 or G-Rk1 binding to Annexin A2-WT in Annexin A2 over-expressed cancer cells. As G-Rg5 and G-Rk1 failed to interact with Annexin A2-K302A, G-Rg5 or G-Rk1 could not inactivate the other pathway triggered NF-KB activation (Figs. 5, $6 \mathrm{~A}$ and $6 \mathrm{~B}$ ), presenting little anti-cancer activity in Annexin A2-K302A over-expressed HepG2 cells (Fig. 6). We further examined the effect of G-Rg5 and Rk1 on NF-KB activity in various cancer cells, including SW480, PC3, HeLa and Huh7, as well as noncancerous HEK-293T cells and normal CCC-HEL1 cells. G-Rg5 or G-Rk1 significantly inhibited NF$\mathrm{KB}$ activity in Annexin A2 over-expressed cells like SW480, PC3, HeLa as did in HepG2 cells, but not in Huh7, a liver cancer cell line with low expression of Annexin A2. Interestingly neither compound inhibited the NF-KB activity in noncancerous HEK-293T cell and normal CCC-HEL1 cells (Fig. S1). These data suggested that G-Rg5 or G-Rk1 may serve as a specific anticancer reagent for the treatment of Annexin A2 over-expressed cancers, and this possibility should be examined in future study.

In conclusion, we have identified two specific smallmolecule inhibitors of Annexin A2, G-Rg5 and G-Rk1, which inhibited NF-KB activity and promoted apoptosis. These data supported the notion that the inhibition of Annexin A2 may be a useful strategy to prevent and treat cancers and G-Rg5 and G-Rk1 can serve as a leading compound for targeted cancer treatment. 


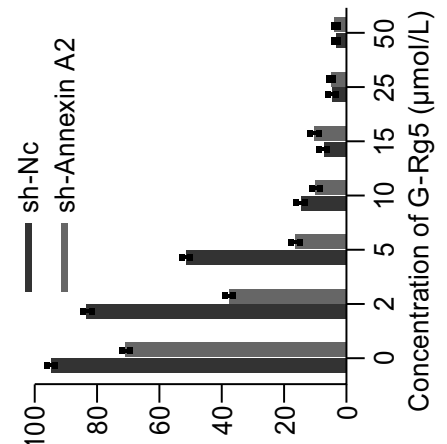

(\%) К१!ı!ฺ๐อ ॥əว

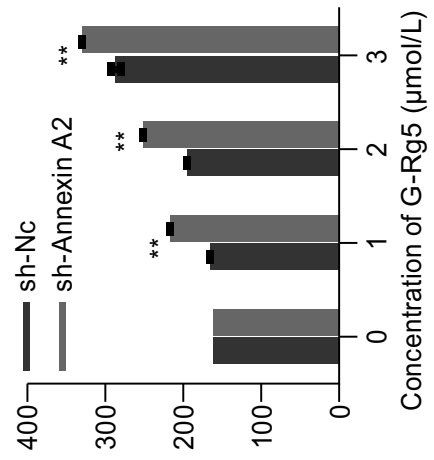

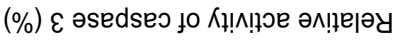

u

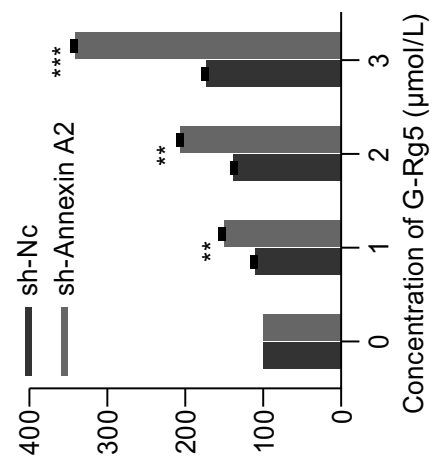

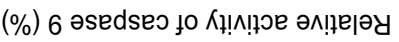

$\infty$

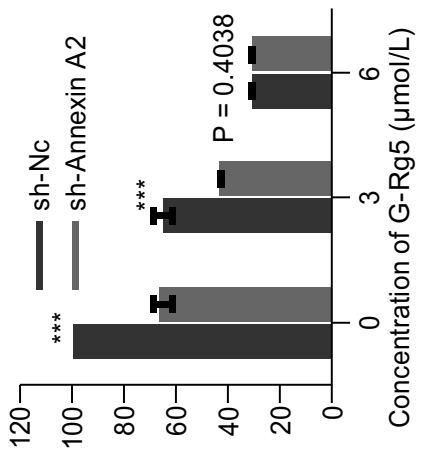

$\varangle$
(\%) Кџ!ı!ฺэе әл!!в|әу

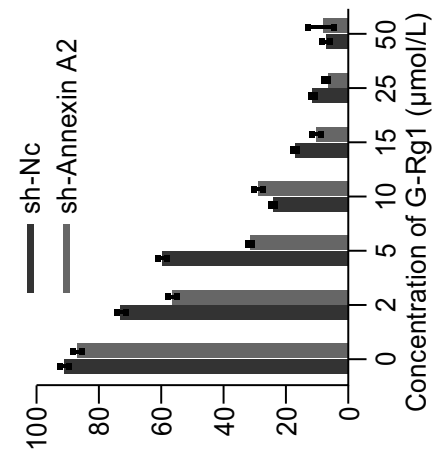

(\%) К१!ฺ!ฺฺอ ॥әว

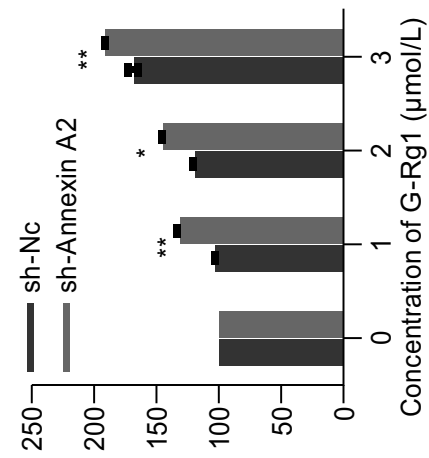

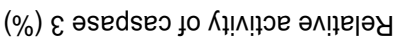

0

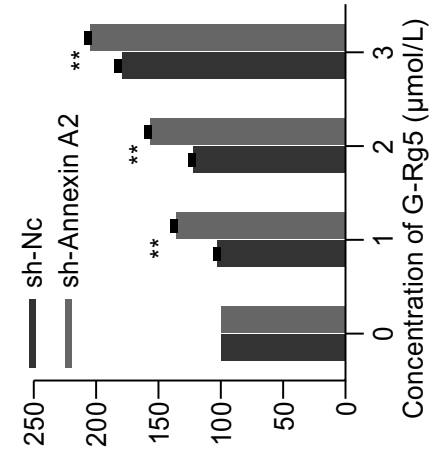

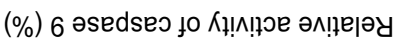

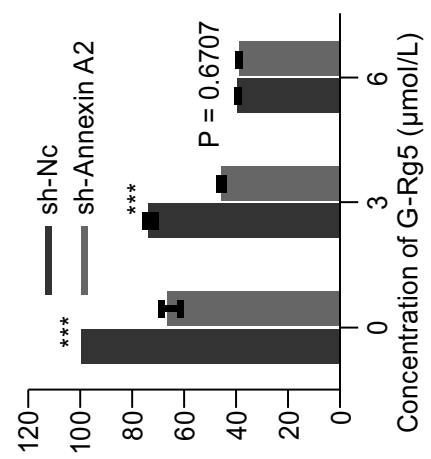

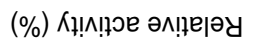

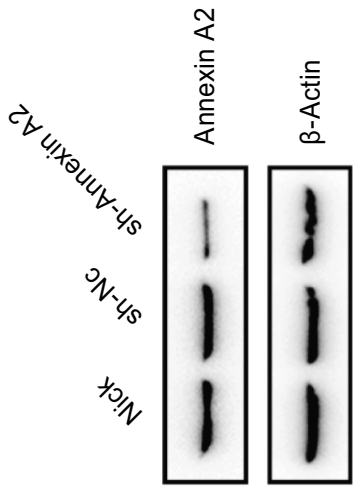

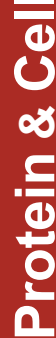

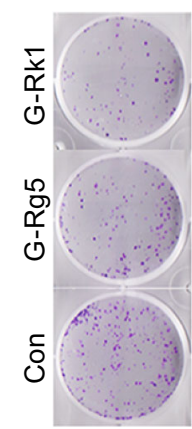

गN-4S

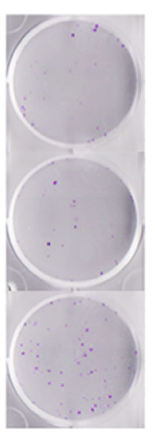

Z u!̣әиu $\forall$ -4s 
4 Figure 4. Knock-down of Annexin A2 enhanced anti-proliferation effect of G-Rg5 and G-Rk1. (A) NF-KB activity was examined by luciferase reporter assay under treatment of G-Rg5 with (sh-Annexin A2) or without (sh-NC) knock-down of Annexin A2. (B and C) Activity of caspase 9 (B) and $3(C)$ was examined under treatment of G-Rg5 with (sh-Annexin A2) or without (sh-NC) knock-down of Annexin A2. (D) Cell viability was examined by MTT for $48 \mathrm{~h}$ under treatment of G-Rg5 with (sh-Annexin A2) or without (sh-NC) knock-down of Annexin A2. (E) NF-kB activity was examined by luciferase reporter assay under treatment of G-Rk1 with (sh-Annexin A2) or without (sh$\mathrm{NC}$ ) knock-down of Annexin A2. ( $F$ and G) Activity of caspase 9 $(F)$ and $3(G)$ was examined under treatment of G-Rk1 with (shAnnexin A2) or without (sh-NC) knock-down of Annexin A2. (H) Cell viability was examined by MTT for $48 \mathrm{~h}$ under treatment of G-Rk1 with (sh-Annexin A2) or without (sh-NC) knock-down of Annexin A2. (I) Plate clone formation assay was examined under treatment of G-Rg5 (6 $\mu \mathrm{mol} / \mathrm{L})$ and G-Rk1 $(6 \mu \mathrm{mol} / \mathrm{L})$ with (sh-Annexin A2) or without (sh-NC) knock-down of Annexin A2. (J) Protein level of Annexin A2 was examined by immunoblot with (sh-Annexin A2) or without (sh-NC) knock-down of Annexin $\mathrm{A} 2$, and $\beta$-actin was shown as a loading control. All data are shown as the mean $\pm \mathrm{SD}$. ${ }^{*} P<0.05$, ${ }^{* *} P<0.01$ and ${ }^{* *} P<$ 0.001 and the experimental points show the average of at least triplicates. All experiments were repeated at least 3 times. Statistical analyses were performed using Student's $t$-test.

\section{MATERIALS AND METHODS}

Cell lines, reagents and plasmids

HepG2 cells were obtained from the American Type Culture Collection (ATCC, Rockville, MA, USA). Dulbecco's Modified Eagle Medium (DMEM) and fetal bovine serum (FBS) were obtained from Gibco BRL (Grand Island, NE, USA). Chemical reagents were listed below: G-Rg5 (Sigma), G-Rk1 (Sigma), phorbol myristate acetate (PMA, Sigma) and etoposide (Sigma). Ginsenosides were dissolved in $75 \%$ alcohol with a final concentration of $12 \mathrm{mmol} / \mathrm{L}$. PMA $(10 \mu \mathrm{g} / \mathrm{mL})$ and etoposide $(25 \mathrm{mg} / \mathrm{mL})$ were dissolved in DMSO. Primary antibodies were listed below: mouse anti-Annexin A2 (Santa Cruz, sc-47696), mouse anti-p50 (Santa Cruz, sc-8414), rabbit anti-p50 (Santa Cruz, sc-7178), mouse anti-C-myc (Santa Cruz, sc-49), rabbit anti-C-myc (Santa Cruz, sc-789), mouse anti-X-IAP (Santa Cruz, sc-55551), rabbit anti-c-IAP1 (Santa Cruz, sc-7943), rabbit anti-c-IAP2 (Santa Cruz, sc-7944), mouse anti-survivin (Santa Cruz, sc-17779) and mouse anti- $\beta$-actin (Santa Cruz, sc-47778). Secondary antibodies were listed below: HRP-conjugated goat anti-mouse IgG (Pierce), HRP-conjugated goat anti-rabbit IgG (Pierce), Су ${ }^{\text {тм } 3}$ affinipure donkey anti-mouse IgG (Jackson ImmunoResearch Inc., PA, USA), and Alexa Fluor ${ }^{\circledR} 488$ affinipure donkey anti-Rabbit lgG (Jackson ImmunoResearch Inc., PA, USA). Genes of human Annexin A2 and human NF-KB p50 subunit were amplified by PCR, and cloned into pEXS-CG (GST-tag at C-terminal, provided by Professor Fei Sun's group, at the Institute of Biophysics of Chinese Academy of Sciences). Prokaryotic vectors were gained that allowed expression of non-tagged Annexin A2 ( $p E X S-A n n e x i n ~ A 2-W T)$, non-tagged NF-kB p50 subunit ( $p E X S-p 50$ ), and C-terminal GST-tagged Annexin A2 ( $p E X S$ CG-Annexin A2-WT). A single point mutation was engineered within Annexin A2-expressing vector, with resulting vectors called $p E X S$ Annexin A2-K302A and pEXS-CG-Annexin A2-K302A. The sequences of both Annexin A2-WT and Annexin A2-K302A were cloned into pcs4 (C-myc-tag at C-terminal), with resulting vectors called pcs4Annexin A2-WT-myc and pcs4-Annexin A2-K302A-myc. Short hairpin RNA (shRNA) vector, pGPU6-GFP-Neo-Annexin A2 (1496), was obtained to knock down Annexin A2 expression in RNA interference assays (GenePharma, Jiangsu, China). The luciferase reporter assays were performed with the following plasmids: pNFKB-TA-luc (Beyotime, Shanghai, China) and pRL-CMV (Promega, WI, USA).

\section{Molecular docking}

We downloaded the three-dimensional structure of G-Rg5 (PubChem CID: 44416768) and G-Rk1 (PubChem CID: 11499198) from the NCBI Pubchem Compound database (http://www.ncbi.nlm.nih. gov/pccompound), and we downloaded the crystal structure of Annexin A2 (PDB ID: 2HYU) from the RCSB Protein Data Bank (http://www.rcsb.org/pdb). Molecular docking was performed with AutoDock tools (version 4.2.6) with the default setting, based on the Lamarckian Genetic Algorithm (Scripps Research Institute, La Jolla, CA, USA). We processed the optimum structure of the complex with the Discovery Studio 4.0 Visualizer (BIOVIA, CA, USA).

\section{Purification of prokaryotic-expressed Annexin A2}

The E. coli expression strain, BL21 (DE3), was transformed with pEXS-CG-Annexin A2, and cultured in Luria-Bertani (LB) liquid medium with $50 \mu \mathrm{g} / \mathrm{mL}$ ampicillin at $37^{\circ} \mathrm{C}$ until the density reached an $\mathrm{OD}_{600}$ of 1.5 . Cells were cooled to $16^{\circ} \mathrm{C}$ and cultured for another $12 \mathrm{~h}$ at $16^{\circ} \mathrm{C}$ with $1.0 \mathrm{mmol} / \mathrm{L}$ IPTG for protein expression. Then, cells were harvested by centrifuging at $6,000 \mathrm{rpm}$ (JA10 rotor, Beckman) for $12 \mathrm{~min}$. The cell pellet was resuspended in pre-cooled lysis buffer (PBS containing $1 \mathrm{mg} / \mathrm{mL}$ lysozyme, $1 \mathrm{mmol} / \mathrm{L}$ DTT and $1 \mathrm{mmol} / \mathrm{L}$ PMSF), placed on ice, and ultra-sonicated for cell lysis. The lysed cells were separated with centrifugation at $12,000 \mathrm{rpm}$ (JA25.50 rotor, Beckman) for $40 \mathrm{~min}$, and the supernatant was loaded onto a GST-affinity chromatography column. The column was washed with pre-cooled PBS containing $1 \mathrm{~mol} / \mathrm{L} \mathrm{NaCl}, 1 \mathrm{mmol} / \mathrm{L}$ DTT and $1 \mathrm{mmol} / \mathrm{L}$ PMSF. Then, we added $10 \mu \mathrm{g}$ of human HRV $3 \mathrm{C}$ protease (TAKARA) to the column, and incubated the column at $4^{\circ} \mathrm{C}$ overnight to allow cleavage of the GST-tag at the C-terminus of the protein. The eluted fraction was then loaded onto a Superdex75 $16 / 600$ column (GE Healthcare) and eluted at a flow rate of $1.0 \mathrm{~mL} / \mathrm{min}$. Fractions were pooled and concentrated to $10 \mathrm{mg} / \mathrm{mL}$ with a 10-kDa cut-off centrifuge filter (Millipore).

The Annexin A2-K302A mutant was purified with the same procedure. 
A
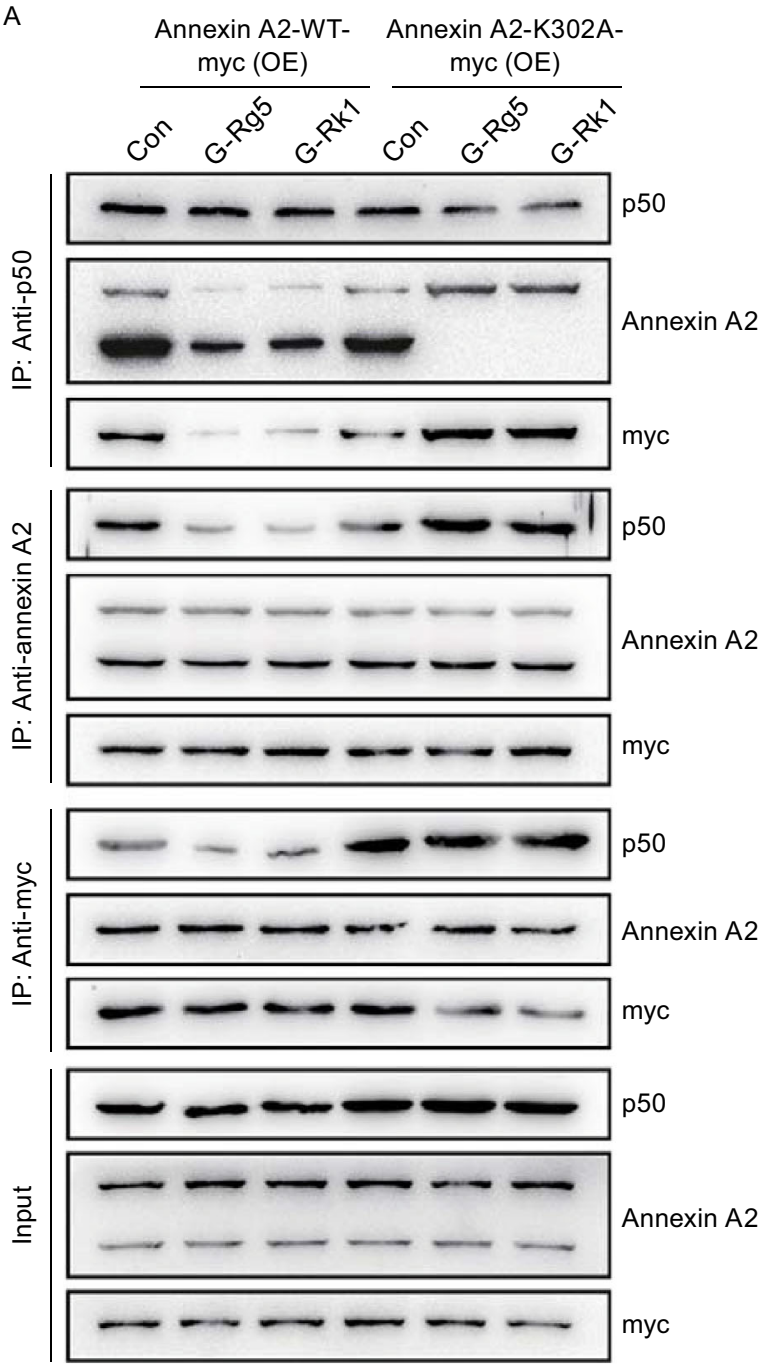

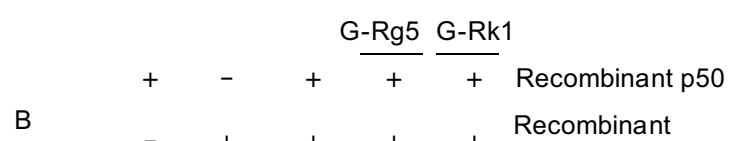

$-\quad+\quad+\quad+\quad+\begin{aligned} & \text { Recombinant } \\ & \text { Annaxin A2-K302A }\end{aligned}$
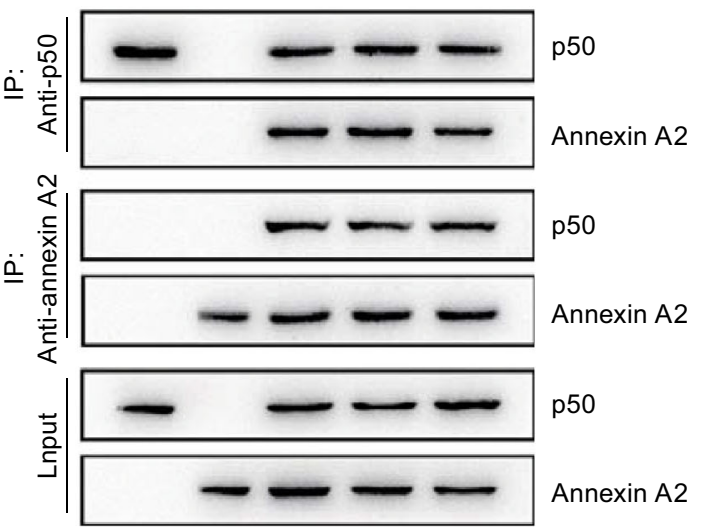

C
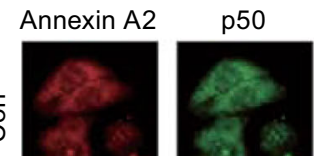

DAPI
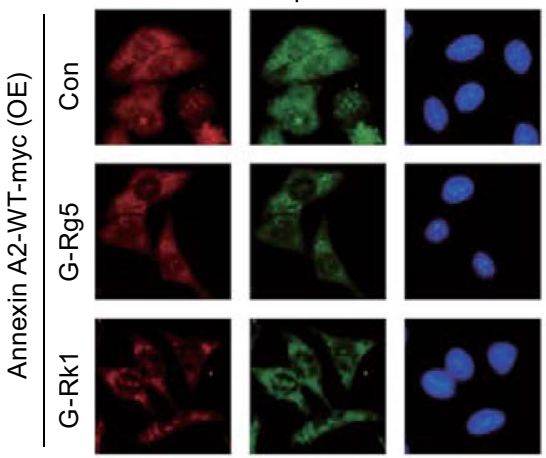

Merge
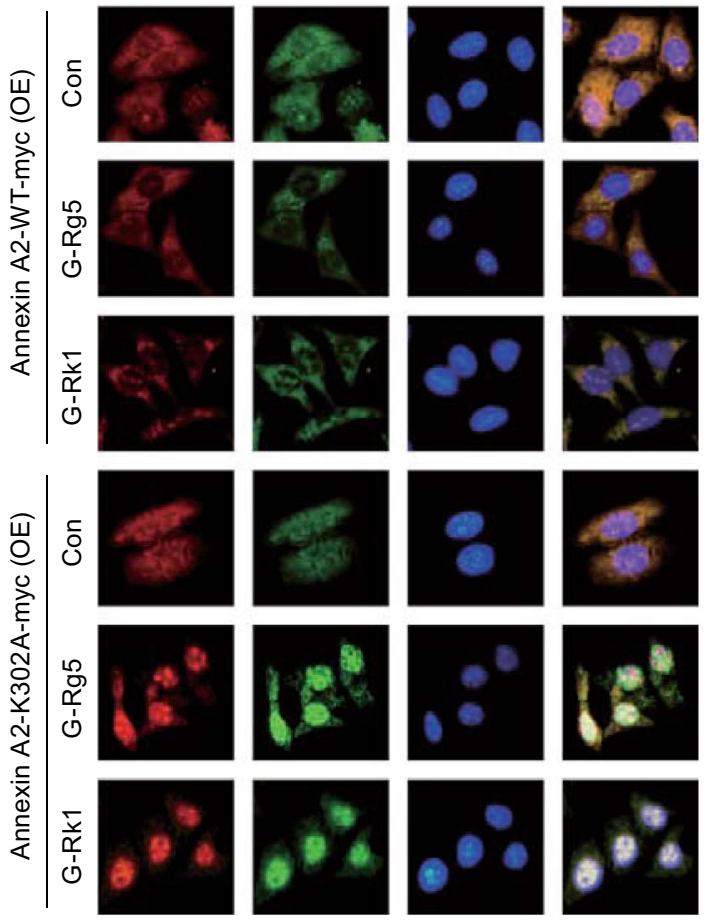

Figure 5. Annexin A2-K302A blocked the inhibitory effect of G-Rg5 and G-Rk1 on the interaction between Annexin A2 and NF-KB p50 subunit and their nuclear co-localization. (A) HepG2 cells were transfected with Annexin A2-WT-myc and Annexin A2K302A-myc, and immunoprecipitation was performed with whole-cell lysate under treatment with G-Rg5 (6 $\mu \mathrm{mol} / \mathrm{L}), \mathrm{G}-\mathrm{Rk} 1$ (6 $\mu \mathrm{mol} / \mathrm{L})$ and examined by an immunoblot. (B) Immunoprecipitation was performed with prokaryotic cells-expressed Annexin A2-K302A and NF-kB p50 subunit under treatment with G-Rg5 $(6 \mu \mathrm{mol} / \mathrm{L})$ and G-Rk1 $(6 \mu \mathrm{mol} / \mathrm{L})$, and the interaction was analyzed by an immunoblot. (C) HepG2 cells were transfected with Annexin A2-WT-myc and Annexin A2-K302A-myc, and the subcellular distribution of Annexin A2 and NF-kB p50 subunit was examined by immunofluorescence under treatment with G-Rg5 (6 $\mu \mathrm{mol} / \mathrm{L})$ and G-Rk1 (6 $\mu \mathrm{mol} / \mathrm{L})$, and DAPI showed the nuclear region. 


\section{Thermal shift assay}

In vivo thermal shift assay (cellular thermal shift assay, CTSA): HepG2 cells $\left(3 \times 10^{7}\right)$ were seeded into a $100-\mathrm{mm}$ culture plate with $12 \mu \mathrm{mol} / \mathrm{L}$ of G-Rg5 or G-Rk1 and cultured for $1 \mathrm{~h}$. Control cells were incubated with the same volume. Cells were cultivated and counted, followed by resuspending in PBS (containing $1 \mathrm{mmol} / \mathrm{L} \mathrm{PMSF}$ ) to a final density of $2 \times 10^{7} / \mathrm{mL}$. Then cells were subpackaged into 12 PCR tubes, with $100 \mu \mathrm{L}$ per PCR tube, and heated with a thermal gradient from $40^{\circ} \mathrm{C}$ to $73^{\circ} \mathrm{C}$, for $3 \mathrm{~min}$. After freeze-thawed twice with liquid nitrogen, the supernatant was separated by centrifugation at $20,000 \times g$ for $20 \mathrm{~min}$ and collected. $20 \mu \mathrm{L}$ of the supernatant was loaded onto an SDS-PAGE gel, followed by an immunoblot.

In vitro thermal shift assay: Purified Annexin A2 protein was diluted with PBS (containing $1 \mathrm{mmol} / \mathrm{L} \mathrm{PMSF}$ ) to a final concentration of $0.2 \mathrm{mmol} / \mathrm{L}(\sim 7 \mu \mathrm{g} / \mathrm{mL})$ and subpackaged into PCR tubes, with $90 \mu \mathrm{L}$ per PCR tube. G-Rg5 or G-Rk1 were diluted with PBS to a final concentration of $100 \mu \mathrm{mol} / \mathrm{L}$, then added to PCR tubes with Annexin A2 protein, forming a dose gradient from $0.2 \mu \mathrm{mol} / \mathrm{L}$ to $10 \mu \mathrm{mol} / \mathrm{L}$. PCR tubes were made up to $100 \mu \mathrm{L}$ with PBS and heated at $55^{\circ} \mathrm{C}$ for $3 \mathrm{~min}$, with the control tube on ice for $3 \mathrm{~min}$. Then $10 \mu \mathrm{L}$ from each tube was loaded onto an SDS-PAGE gel, followed by an immunoblot.

\section{Immunoprecipitation}

In vivo: HepG2 cells $\left(1.6 \times 10^{6}\right)$ were plated into $100-\mathrm{mm}$ culture plates and treated with G-Rg5 (6 $\mu \mathrm{mol} / \mathrm{L}), \mathrm{G}-\mathrm{Rk} 1(6 \mu \mathrm{mol} / \mathrm{L}), \mathrm{PMA}$ $(100 \mathrm{ng} / \mathrm{mL})$ and etoposide $(25 \mu \mathrm{g} / \mathrm{mL})$ for $12 \mathrm{~h}$. Cells were lysed in lysis buffer (Pierce) containing protease inhibitors (Roche) and $1 \mathrm{mmol} / \mathrm{L}$ PMSF. $2 \mathrm{mg}$ of total protein lysates were mixed with $10 \mu \mathrm{L}$ of anti-Annexin A2, anti-p50 antibody or anti-C-myc, and incubated at $4^{\circ} \mathrm{C}$ for $3 \mathrm{~h}$ on a tube rotator. Protein $\mathrm{A} / \mathrm{G}$ beads (Millipore) were washed three times with lysis buffer, and then incubated at $4^{\circ} \mathrm{C}$ for $4 \mathrm{~h}$ with the lysate-antibody complexes. The protein-agarose beads complexes were washed three times with lysis buffer. Samples were then separated with an SDS-PAGE and analyzed with an immunoblot.

In vitro: Cultures of the $E$. coli expression strain, BL21 (DE3), were transformed with pEXS-CG, pEXS-Annexin A2 (label-free) and pEXSp50. Cells were cultivated in LB liquid medium containing $50 \mu \mathrm{g} / \mathrm{mL}$ ampicillin at $37^{\circ} \mathrm{C}$, until the cell density reached an $\mathrm{OD}_{600}$ of 1.5 . Then, cells were cultivated with $1 \mathrm{mmol} / \mathrm{L}$ IPTG for another $12 \mathrm{~h}$. Cells were lysed with ultra-sonication in lysis buffer (100 mmol/L PBS, $125 \mathrm{mmol} / \mathrm{L} \mathrm{NaCl}, 1 \mathrm{mg} / \mathrm{mL}$ lysozyme, and $1 \mathrm{mmol} / \mathrm{L} \mathrm{PMSF}$ ). $1 \mathrm{mg}$ of the protein lysate containing Annexin A2 and another $1 \mathrm{mg}$ of the protein lysate containing p50 were incubated at $4^{\circ} \mathrm{C}$ overnight with $12 \mu \mathrm{mol} / \mathrm{L} \mathrm{G-Rg} 5$ or G-Rk1. As a control, $1 \mathrm{mg}$ of protein lysate that contained neither Annexin A2 nor p50 was incubated in parallel. The remaining steps were performed as described above for the in vivo assay.

\section{Immunofluorescence}

Glass cover slips were placed into the wells of a 24-well plate, and 5 $\times 10^{4}$ HepG2 cells were seeded into each well. After a 16-h incubation, cells were treated with G-Rg5 $(6 \mu \mathrm{mol} / \mathrm{L}), \mathrm{G}-\mathrm{Rk} 1(6 \mu \mathrm{mol} / \mathrm{L})$, PMA (100 $\mathrm{ng} / \mathrm{mL})$ and etoposide $(25 \mu \mathrm{g} / \mathrm{mL})$ for $2 \mathrm{~h}$. Next, cells were fixed with pre-cool methanol at $4^{\circ} \mathrm{C}$ for $5 \mathrm{~min}$. Then, cells were washed twice with PBST (100 mmol/L PBS with $0.5 \%$ Tween-20). The fixed cells were permeabilized with PBST containing $0.2 \%$ Triton $\mathrm{X}-100$ at $4^{\circ} \mathrm{C}$ for $20 \mathrm{~min}$, then washed three times with PBST. Permeabilized cells were incubated with blocking buffer (PBST containing $3 \%$ donkey serum) at room temperature for $1 \mathrm{~h}$, then incubated with a primary antibody (mouse anti-Annexin $\mathrm{A} 2$ and rabbit anti-NF-kB, each diluted 1:200 in PBST with 5\% BSA) for $3 \mathrm{~h}$ at $4^{\circ} \mathrm{C}$. Cells were washed three times with PBST and incubated with a secondary antibody (Cy ${ }^{\mathrm{TM}} 3$ affinipure donkey anti-mouse $\lg \mathrm{g}$ and Alexa Fluor 888 affinipure donkey anti-Rabbit IgG, each diluted $1: 200$ in PBST with $5 \%$ BSA) for $2 \mathrm{~h}$ at room temperature. After the cells were washed twice with PBST, stained with PBST and $0.1 \%$ DAPI (Sigma), and analyzed with a fluorescence microscope.

\section{Cell viability assay}

HepG2 cells were plated $\left(5 \times 10^{3}\right.$ per well) onto 96 -well plates and treated with G-Rg5 or G-Rk1 at the indicated concentrations for $48 \mathrm{~h}$. Cell viability was determined with the MTT assay.

\section{Plate clone formation assay}

HepG2 were plated $\left(1 \times 10^{3}\right.$ per well) onto 6-well plates and treated with G-Rg5 $(6 \mu \mathrm{mol} / \mathrm{L})$ and G-Rk1 $(6 \mu \mathrm{mol} / \mathrm{L})$ at the indicated concentrations for 1 week. Then cells were washed twice with PBS and fixed with precooled methanol for $10 \mathrm{~min}$, followed by crystal violet staining for $5 \mathrm{~min}$. Then cells were washed twice with PBS and photographed.

\section{Quantitative real-time PCR (qRT-PCR)}

Whole-cell RNA was isolated with TRIzol (Invitrogen). Then, 5- $\mu \mathrm{g}$ aliquots of whole-cell RNA were used for CDNA synthesis with the EasyScript Reverse Transcriptase kit (Transgen). QRT-PCR was performed on Applied Biosystem 7500 Real-time PCR system (Applied Biosystem. Inc) and TransStart Tuo Green qPCR SuperMix (Transgen). The amplification was performed with a three-step program, 1 cycle at $94^{\circ} \mathrm{C}$ for $30 \mathrm{~s}$, followed by 45 cycles of $94^{\circ} \mathrm{C}$ for $5 \mathrm{~s}$, $50^{\circ} \mathrm{C}$ for $15 \mathrm{~s}$, and $72^{\circ} \mathrm{C}$ for $10 \mathrm{~s}$, with signal collecting steps after annealing and extending for $34 \mathrm{~s}$.

\section{Statistical analysis}

Data are presented as the mean \pm S.D. Statistical significance was calculated with the Student's $t$-test. 


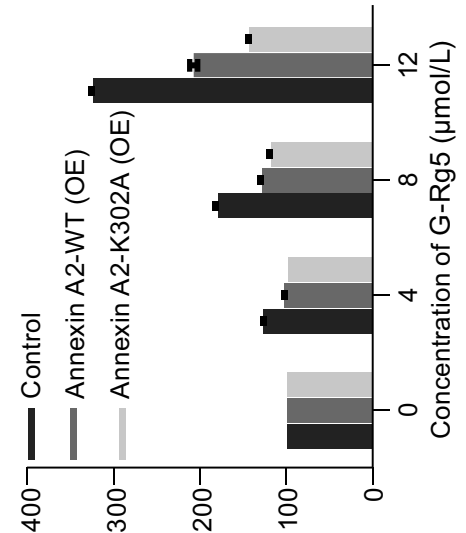

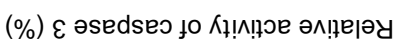
u

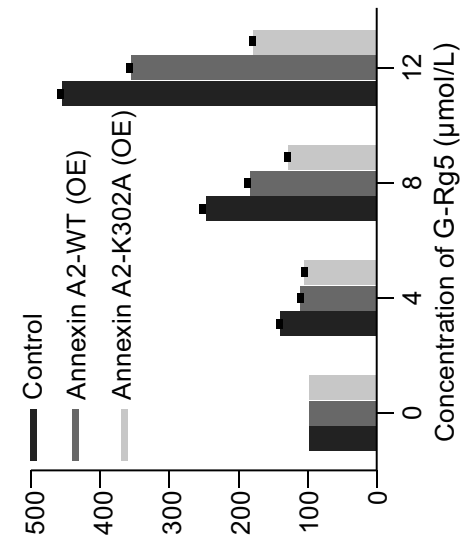

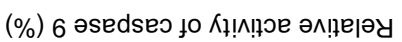

$\infty$

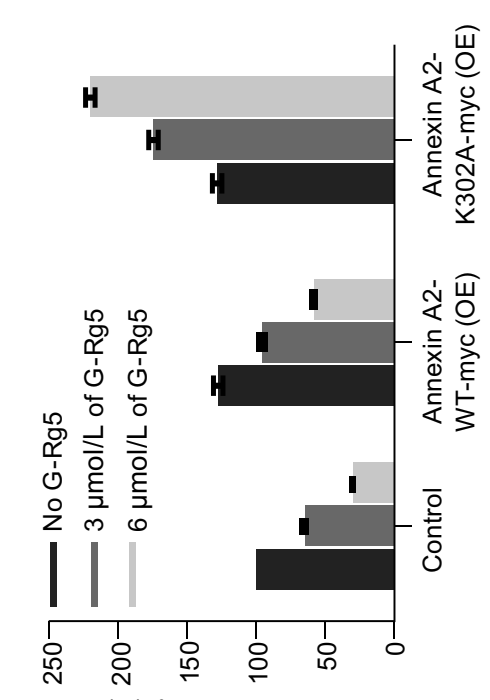

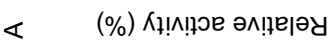

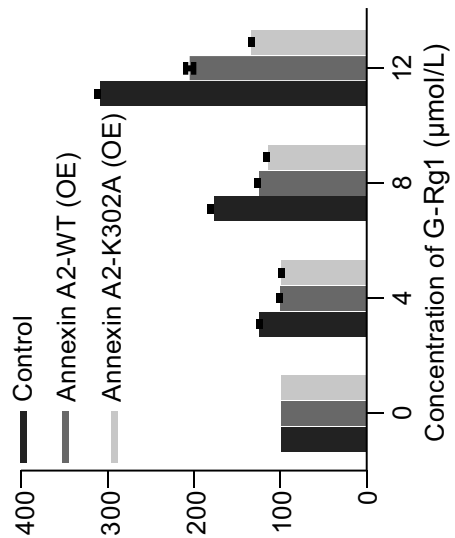

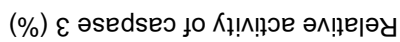

ᄂ

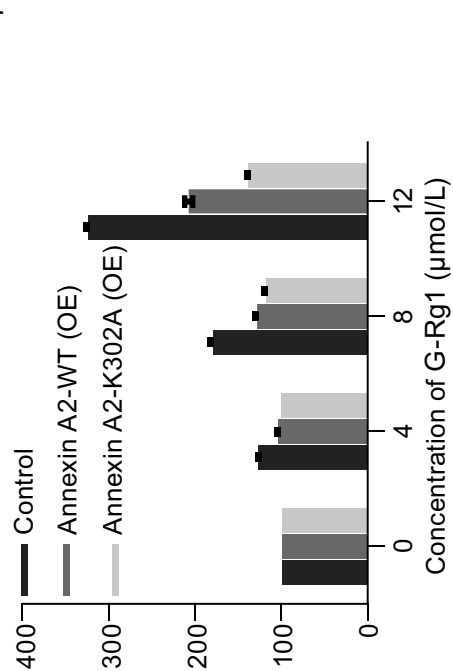

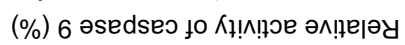
ш
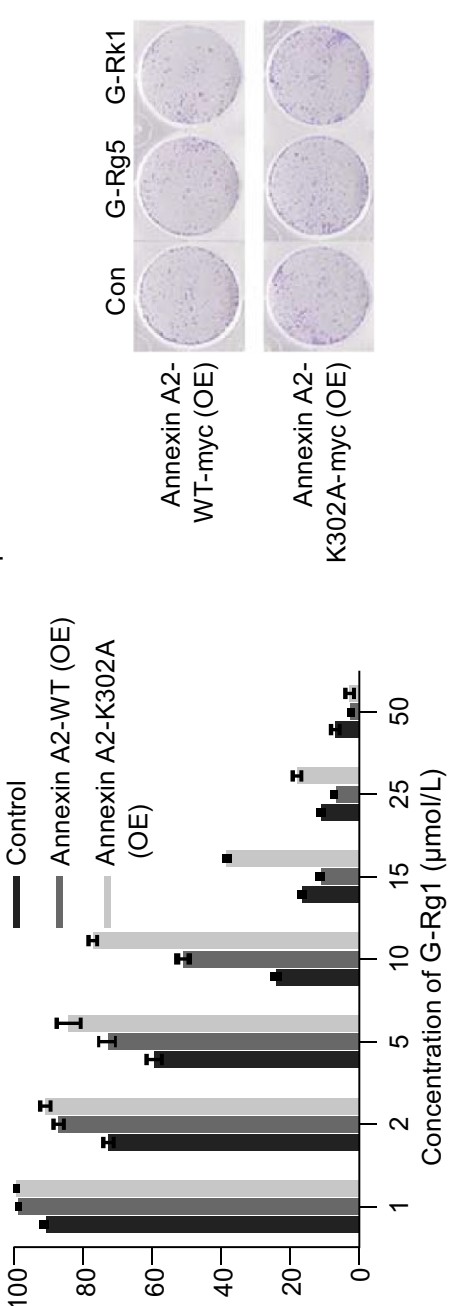

I

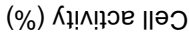

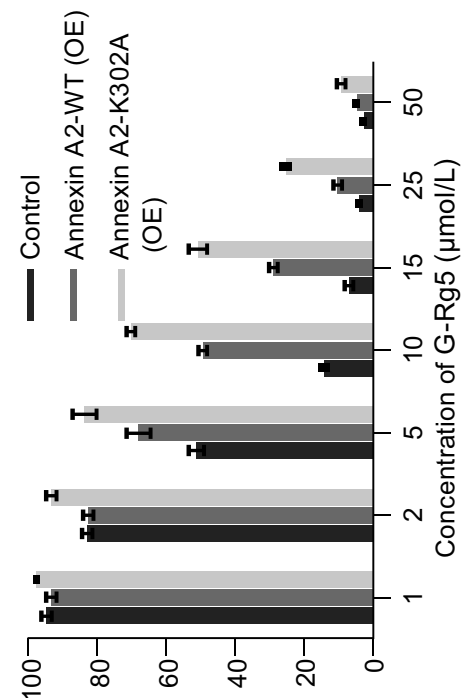

(1)

(\%) Кฺ!ฺ!ฺ৩อ ॥əว 
Figure 6. Annexin A2-K302A protected cells from antiproliferation effect of G-Rg5 and G-Rk1. (A) NF-kB activity was examined by luciferase reporter assay under treatment of G-Rg5 with Annexin A2-WT-myc and Annexin A2-K302A-myc overexpressed in HepG2 cells. (B and C) Activity of caspase 9 (B) and $3(\mathrm{C})$ was examined under treatment of G-Rg5 with Annexin A2-WT-myc and Annexin A2-K302A-myc overexpressed in HepG2 cells. (D) Cell viability was examined by MTT for $48 \mathrm{~h}$ under treatment of G-Rg5 with Annexin A2-WTmyc and Annexin A2-K302A-myc overexpressed in HepG2 cells. (E) NF-KB activity was examined by luciferase reporter assay under treatment of G-Rk1 with Annexin A2-WT-myc and Annexin A2-K302A-myc overexpressed in HepG2 cells. ( $F$ and $\mathrm{G})$ Activity of caspase $9(\mathrm{~F})$ and $3(\mathrm{G})$ was examined under treatment of G-Rk1 with Annexin A2-WT-myc and Annexin A2K302A-myc overexpressed in HepG2 cells. (H) Cell viability was examined by MTT for $48 \mathrm{~h}$ under treatment of G-Rk1 with Annexin A2-WT-myc and Annexin A2-K302A-myc overexpressed in HepG2 cells. (I) Plate clone formation assay was examined under treatment of G-Rg5 $(6 \mu \mathrm{mol} / \mathrm{L})$ and $\mathrm{G}-\mathrm{Rk} 1$ (6 $4 \mathrm{~mol} / \mathrm{L})$ with Annexin A2-WT-myc and Annexin A2-K302Amyc overexpressed in HepG2 cells. All data are shown as the mean $\pm S D$ and the experimental points show the average of at least triplicates. All experiments were repeated at least 3 times.

\section{ACKNOWLEDGMENTS}

This study was funded by Provincial Project for Industrial Innovation Special Fund of Jilin Province (2017) and Special Project for Province and University Construction Plan of Jilin Province (SXGJXX2017-13).

\section{ABBREVIATIONS}

BSA, bovine serum albumin; cDNA, complementary DNA; CTSA, cellular thermal shift assay; DAPI, 4',6-diamidino-2-phenylindole; DMEM, Dulbecco's Modified Eagle Medium; DMSO, dimethyl sulfoxide; DTT, DL-Dithiothreitol; HCC, hepatocellular carcinoma; IPTG, isopropy- $\beta$-D-thiogalactoside; MTT, 3-(4,5-dimethyl-2-thiazolyl)-2,5-diphenyl-2-H-tetrazolium bromide; NF-KB, nuclear factor kappa B; PBS, phosphate buffer saline; PBST, phosphate buffer saline with Tween-20; PCR, polymerase chain reaction; PMA, propylene glycol methyl ether acetate; PMSF, phenylmethanesulfonyl fluoride; qRT-PCR, quantitative real-time polymerase chain reaction; rpm, revolutions per minute; SDS-PAGE, sodium dodecyl sulfate polyacrylamide gel electrophoresis; STAT3, signal transducer and activator of transcription 3

\section{COMPLIANCE WITH ETHICS GUIDELINES}

Yu-Shi Wang, He Li, Yang Li, Hongyan Zhu and Ying-Hua Jin declare they have no conflict of interest.

\section{OPEN ACCESS}

This article is distributed under the terms of the Creative Commons Attribution 4.0 International License (http://creativecommons.org/ licenses/by/4.0/), which permits unrestricted use, distribution, and reproduction in any medium, provided you give appropriate credit to the original author(s) and the source, provide a link to the Creative Commons license, and indicate if changes were made.

\section{REFERENCES}

Alexandersavino CV, Hayden MS, Richardson C et al (2016) Doxycycline is an NF-KB inhibitor that induces apoptotic cell death in malignant T-cells. Oncotarget 7(46):75954-75967

Attele AS, Wu JA, Yuan CS (1999) Ginseng pharmacology: multiple constituents and multiple actions. Biochem Pharmacol 58:16851693

Chen CY, Lin YS, Chen CL et al (2015) Targeting annexin A2 reduces tumorigenesis and therapeutic resistance of nasopharyngeal carcinoma. Oncotarget 6(29):26946-26959

Chuthapisith S, Bean BE, Cowley G et al (2009) Annexins in human breast cancer: Possible predictors of pathological response to neoadjuvant chemotherapy. Eur J Cancer 45:1274-1281

Das S, Shetty P, Valapala M et al (2010) Signal transducer and activator of transcription 6 (STAT6) is a novel interactor of Annexin A2 in prostate cancer cells. Biochemistry 49(10):22162226

Deng S, Wang J, Hou L, Li J, Chen G, Jing B, Zhang X, Yang Z (2013) Annexin A1, A2, A4 and A5 play important roles in breast cancer, pancreatic cancer and laryngeal carcinoma, alone and/or synergistically. Oncol Lett 5:107-112

Dolcet X, Llobet D, Pallares J, Matias-Guiu X (2005) NF-kB in development and progression of human cancer. Virchows Arch 446:475-482

Duncan R, Carpenter B, Main LC, Telfer C, Murray GI (2008) Characterisation and protein expression profiling of annexins in colorectal cancer. Br J Cancer 98:426-433

Ecsédi P, Kiss B, Gógl G et al (2017) Regulation of the equilibrium between closed and open conformations of Annexin A2 by $\mathrm{N}$-terminal phosphorylation and S100A4-binding. Structure 25 (8):1195.e5-1207.e5

Gerke V, Creutz CE, Moss SE (2005) Annexins: linking $\mathrm{Ca}^{2+}$ signalling to membrane dynamics. Nat Rev Mol Cell Biol 6:449461 [PubMed: 15928709]

Hanahan D, Weinberg RA (2000) The hallmarks of cancer. Cell 100:57-70

Hayden MS, Ghosh S et al (2008) Shared principles in NF-KB signaling. Cell 132(3):344-362

Jung H, Kim JS, Kim WK et al (2015) Intracellular annexin A2 regulates NF-KB signaling by binding to the p50 subunit: implications for gemcitabine resistance in pancreatic cancer. Cell Death Dis 6(1):e1606

Kesavan K, Ratliff J, Johnson EW et al (2010) Annexin A2 is a molecular target for TM601, a peptide with tumor-targeting and anti-angiogenic effects. J Biol Chem 285(7):4366 
Klionsky DJ et al (2012) Guidelines for the use and interpretation of assays for monitoring autophagy. Autophagy 8:445-544

Kwon M, Jang H, Kim EH et al (2016) Efficacy of poly (ADP-ribose) polymerase inhibitor olaparib against head and neck cancer cells: Predictions of drug sensitivity based on PAR-p53-NF-kB interactions. Cell Cycle 15(22):3105

Lee SM (2015) Anti-inflammatory effects of ginsenosides Rg5, Rz1, and Rk1: inhibition of TNF- $\alpha$-induced NF-kB, COX-2, and iNOS transcriptional expression. Phytother Res 28(12):1893-1896

Longerich T, Haller MT, Mogler C et al (2011) Annexin A2 as a differential diagnostic marker of hepatocellular tumors. Pathol Res Pract 207(1):8-14

Ma RL, Shen LY, Chen KN (2014) Coexpression of ANXA2, SOD2 and HOXA13 predicts poor prognosis of esophageal squamous cell carcinoma. Oncol Rep 31:2157-2164

Moreau K, Ravikumar B, Renna M, Puri C, Rubinsztein DC (2011) Autophagosome precursor maturation requires homotypic fusion. Cell 146:303-317

Moss SE, Morgan RO (2004) The annexins. Genome Biol 5:219. [PubMed: 15059252]

Ohno Y, Izumi M, Kawamura T, Nishimura T, Mukai K, Tachibana M (2009) Annexin II represents metastatic potential in clearcell renal cell carcinoma. Br J Cancer 101:287-294

Perkins ND (2012) The diverse and complex roles of NF-KB subunits in cancer. Nat Rev Cancer 12:121-132

Réty S, Sopkova J, Renouard M, Osterloh D, Gerke V, Tabaries S, Russo-Marie F, Lewit-Bentley A (1999) The crystal structure of a complex of $\mathrm{p} 11$ with the annexin II N-terminal peptide. Nat Struct Biol 6:89-95

Shetty PK, Thamake SI, Biswas S, Johansson SL, Vishwanatha JK (2012) Reciprocal regulation of annexin A2 and EGFR with Her-2 in Her-2 negative and herceptin-resistant breast cancer. PLoS One 7:e44299

Staquicini DI, Rangel R, Guzmanrojas L et al (2017) Intracellular targeting of annexin A2 inhibits tumor cell adhesion, migration, and in vivo grafting. Sci Rep 7(1):4243

Sun Y, Gao G, Cai J et al (2013) Annexin A2 is a discriminative serological candidate in early hepatocellular carcinoma. Carcinogenesis 34(3):595-604

Takano S, Togawa A, Yoshitomi $\mathrm{H}$ et al (2008) Annexin II overexpression predicts rapid recurrence after surgery in pancreatic cancer patients undergoing gemcitabine-adjuvant chemotherapy. Ann Surg Oncol 15:3157-3168

Toh DF, New LS, Koh HL, Chan EC (2010) Ultra-high performance liquid chromatography/time-of-flight mass spectrometry (UHPLC/ TOFMS) for time-dependent profiling of raw and steamed Panax notoginseng. J Pharm Biomed Anal 52:43-50

Tong W, Jie Y, Jie Z et al (2015) Anxa2 binds to STAT3 and promotes epithelial to mesenchymal transition in breast cancer cells. Oncotarget 6(31):30975-30992

Wang CY, Chen CL, Tseng YL et al (2012) Annexin A2 silencing induces $\mathrm{G} 2$ arrest of non-small cell lung cancer cells through p53dependent and -independent mechanisms. J Biol Chem 287 (39):32512-32524

Woo SM, Min KJ, Seo BR, Kwon TK (2016) Ym155 sensitizes trailinduced apoptosis through cathepsin s-dependent down-regulation of mcl-1 and n NF-KB down-regulation of c-flip expression in human renal carcinoma caki cells. Oncotarget 7(38):6152061532

Yang T, Peng H, Wang J, Yang J, Nice EC, Xie K, Huang C (2013) Prognostic and diagnostic significance of annexin A2 in colorectal cancer. Colorectal Dis 15:e373-e381

Yang SF, Hsu HL, Chao TK, Hsiao CJ, Lin YF, Cheng CW (2014) Annexin A2 in renal cell carcinoma: Expression, function, and prognostic significance. Urol Oncol 33:22.e11-22.e21

Yao H, Zhang Z, Xiao Z et al (2009) Identification of metastasis associated proteins in human lung squamous carcinoma using two-dimensional difference gel electrophoresis and laser capture microdissection. Lung Cancer 65:41-48

Yin DL, Liang YJ, Zheng TS et al (2016) EF24 inhibits tumor growth and metastasis via suppressing NF-kappaB dependent pathways in human cholangiocarcinoma. Sci Rep 6:32167

Zhang HJ, Yao DF, Yao M, Huang H, Wu W, Yan MJ, Yan XD, Chen $J(2012 a)$ Expression characteristics and diagnostic value of annexin A2 in hepatocellular carcinoma. World J Gastroenterol 18:5897-5904

Zhang Q, Ye Z, Yang Q, He X, Wang H, Zhao Z (2012b) Upregulated expression of annexin II is a prognostic marker for patients with gastric cancer. World J Surg Oncol 10:103 